Institute for Community Research and Development

\title{
Local Authority Responses to people with NRPF during the pandemic
}

\section{Interim project findings briefing}

\author{
$21^{\text {st }}$ May 2020
}

Andy Jolly, ICRD, University of Wolverhampton,

Bozena Sojka, ICRD, University of Wolverhampton

Eve Dickson, Project 17

Fizza Qureshi, Migrants' Rights Network

Dave Stamp, ASIRT

Benjamin Morgan, PILC 


\section{Acknowledgments}

The research project which this initial briefing draws on was funded by a grant from Paul Hamlyn Foundation, the research team are grateful to all the organisations who contributed to the call for evidence, to Ilona Pinter and Bridget Anderson for their support and advice, and to Jean Demars, Kasia Makowska and Danielle Manson for assistance with data collection.

\section{Suggested citation}

Jolly, A., Sojka, B., Dickson, E., Qureshi, F., Stamp, D., Morgan, B. (2020) Local Authority Responses to people with NRPF during the pandemic: Interim project findings briefing. ICRD, Wolverhampton 


\section{Key findings}

- There was a lack of information available for people with NRPF: Only 5 of the 151 local authorities in England had publically available NRPF policies which were accurate, up to date and contained referral contact details during the pandemic, and more than 40 percent of local authority websites either did not have any information at all about NRPF on their website.

- Most local authorities had not shared updated information for people with NRPF since the pandemic: More than 90 percent of local authority websites did not have updated information on support for people with NRPF during the pandemic, and 6 out of 10 organisations who responded to the call for evidence had not received updated information from their local authority since the start of the pandemic.

- Numbers of service users with NRPF who had COVID-19 symptoms were relatively small, but organisations reported that those who did have symptoms were particularly likely to die or become seriously ill: More than half of organisations that responded to the call for evidence knew of service users who had been diagnosed with COVID-19. Although most knew of relatively small numbers who were experiencing symptoms, of those who did, nearly half had become seriously ill or died.

- Service users with NRPF struggled to access food, shelter and subsistence support during the pandemic: The most commonly reported impact of the pandemic was not having enough food. More than 8 out of 10 organisations identified this as a concern for their service users. The most commonly reported difficulty across all user groups was being refused support from the local authority. For those already accessing support, for children and families the most commonly experienced difficulty was inadequate accommodation making it difficult to self-isolate. For adults with care needs it was being unable to get in contact with the local authority. For homeless adults, the most commonly reported problem was having no provision for their food or subsistence needs. 


\section{Contents}

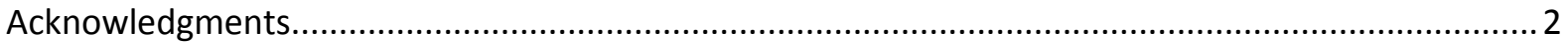

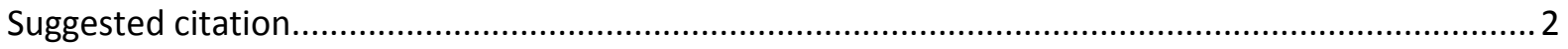

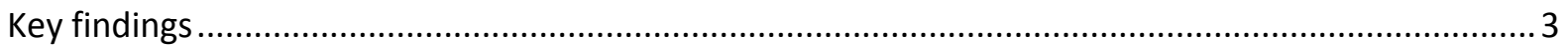

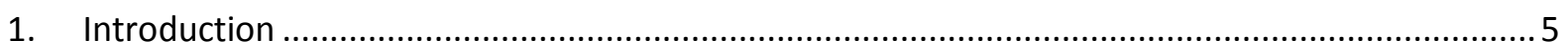

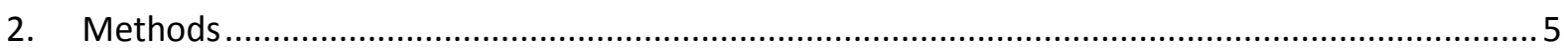

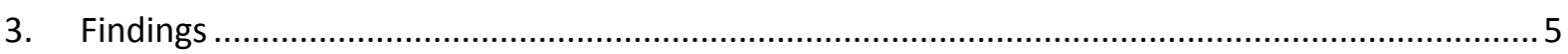

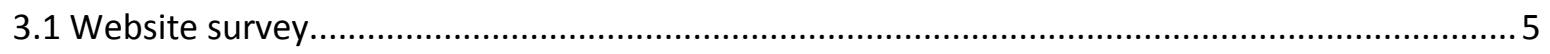

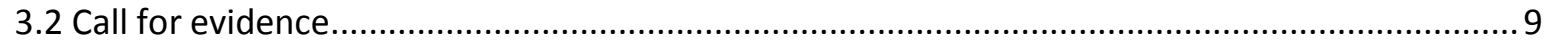

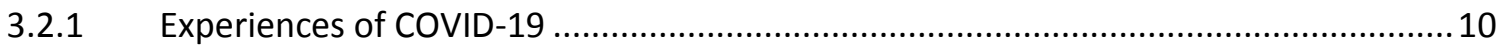

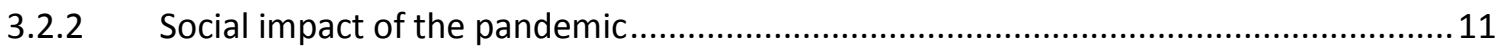

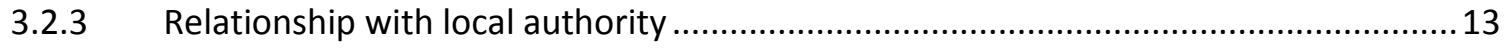

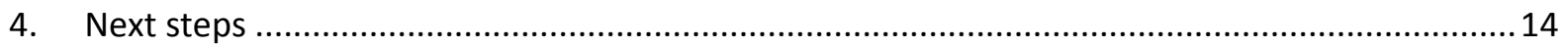

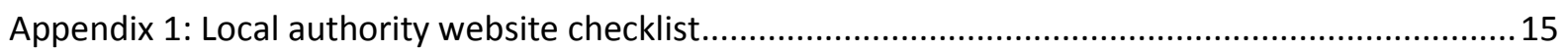

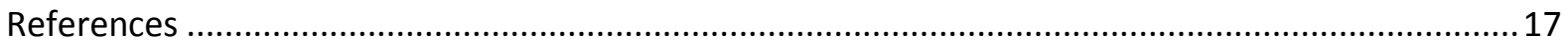




\section{Introduction}

This project was borne out of a concern that people with No Recourse to Public Funds (NRPF) were being left out of the measures to protect people from the impact of the COVID-19 pandemic. Despite the instructions from the Ministry of Housing, Communities and Local Government to 'bring everyone in' (MHCLG, 2020), the authors found from their own practice, and from the experience of others, examples of situations where both families and single adults were being disproportionately impacted by the pandemic. Case studies published this week by organisations working with migrant families highlight this concern (Children's society, ASIRT, The Unity Project, South London Refugee Association, Hackney Migrant Centre, 2020).

There is increasing evidence that those with NRPF face high levels of social exclusion and were unable to access welfare support even prior to the pandemic (Farmer, 2017; Jolly, 2018; Dickson, 2019, Pinter, I., Compton, Parhar \& Majid, 2020), but more research is needed to understand how the current crisis is affecting people who are subject to the NRPF condition.

This briefing highlights some initial findings from a research project which aims to understand the impact of the pandemic on people with NRPF; the response of local authorities; and to identify areas of good practice which can be built on to safeguard the welfare of people with NRPF.

\section{Methods}

The project uses a range of research methods:

1. Survey of local authority websites

2. Call for evidence from voluntary sector organisations

3. Daily welfare diaries completed by people with NRPF

This interim briefing draws on findings from methods 1 and 2 carried out in April and early May 2020. Welfare diaries will commence during the first week of June, and the local authority website survey will be repeated in early June to assess the extent that local authorities have updated the information they are providing to people with NRPF.

\section{Findings}

\subsection{Website survey}

The websites of all unitary and upper tier authorities in England were surveyed between $22^{\text {nd }}$ April and $8^{\text {th }}$ May using the checklist in appendix 1 . These scores were then converted into four indicators based on the likelihood of a person with NRPF being able to find information about support during the COVID-19 pandemic. Local authorities were graded between inadequate and outstanding based on the findings from their websites. The thresholds and indicators for these scores are outlined in Figure 1. 


\section{8-9 points - Outstanding}

This authority is an example of best practice. The authority has a publically available NRPF policy which has been updated since the pandemic. The information in the policy is accurate. There is specific information about different categories of support such as the Care Act and Section 17 of the Children Act, and there is likely to be gender specific policies, as well as clear contact or referral details for service users and their advisors.

\section{5-7 points - Good}

This authority has an NRPF policy and information which is both accurate and usually up to date. There may even be specific information about different support categories, and are likely to be referral or contact details for people with NRPF. There may be some gaps in detail on the website, but, someone seeking support from this authority would be likely to find most of the information they need.

\section{1-4 points - Needs improvement}

There is some information on the website about support for people with NRPF, but this is likely to fall short of a full policy, or is inaccurate or misleading. There may not be contact details for referral, or specific information for particular categories of support. Someone trying to find out how to get support during the pandemic for someone with NRPF would be unlikely to find this information.

\section{$-2-0$ points - Inadequate}

This local authority does not have an NRPF policy on their website, if there is any information at all it is out of date, factually inaccurate or misleading. No contact details are available, and it would not be possible for someone with NRPF to be able to find out how to get support during the pandemic.

None of the websites reached the threshold for a score of 'outstanding' and only five met the threshold for a rating of 'good' - where there was an NRPF policy and information which was both accurate and often up to date, with some specific information about different support categories. These were Brent, Hackney, Wolverhampton, Manchester and Trafford (see figure 2).

\section{Figure 2: Local authority website scores}

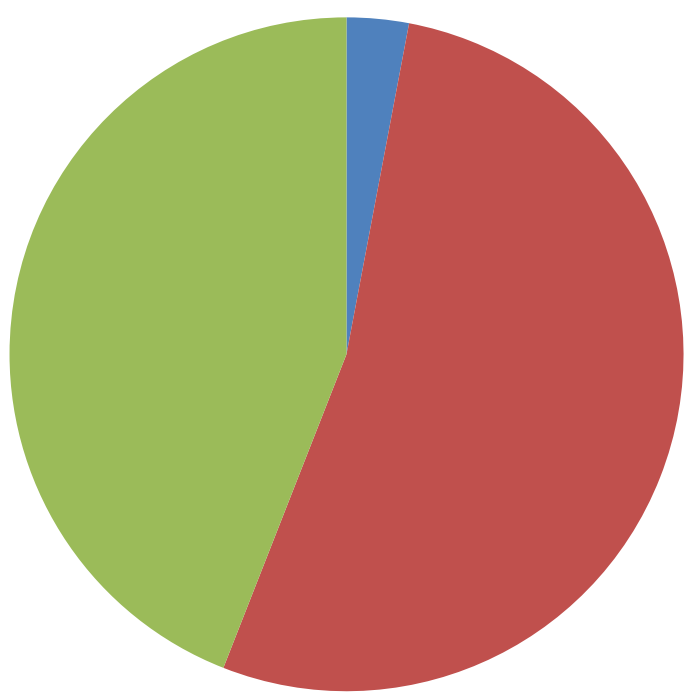

Good (44\%)

Needs Improvement (53\%)

- Inadequate (44\%) 
Brent Borough Council included NRPF issues in their information about homelessness, domestic abuse, and referral details for the children's team. However, there was no COVID-19 specific update, In contrast, Hackney had a COVID-19 update including what rough sleepers were able to receive during the pandemic with contact details and a clear statement for homeless people with NRPF:

"We have been working hard to ensure rough sleepers are not on the streets during the coronavirus pandemic. Self-contained accommodation, food and support is available for all rough sleepers including those with no recourse to public funds." (Hackney 2020).

The City of Wolverhampton Council had a policy which explicitly referred to Zambrano carers, with detailed guidance on support policies, referral contact details, and a homelessness strategy informed by local partners in the refugee and migrant sector. Manchester City Council had a policy and detail on specific groups including older people, people suffering from domestic abuse and contact details for support. Nonetheless, there was still a concerning emphasis on NRPF in their Counter Fraud and Irregularity Strategy (Manchester, 2020). Finally, Trafford Borough Council had an NRPF policy, information on housing, violence against women and maternity support.

The majority of websites were rated as 'needing improvement' indicating that there was some information on the website about support for people with NRPF, but this either fell short of a full policy, or contained inaccurate/misleading information, and therefore someone trying to find out how to get support during the pandemic for someone with NRPF would be unlikely to find this information (see figure 3).

Most worryingly, over 40 percent of local authority websites either did not have any information at all about NRPF on their website, or had information that was out of date, factually inaccurate or misleading and were therefore categorised as inadequate because it would not be possible for someone with NRPF to be able to find out how to get support during the pandemic. The most common reason for being rated as needing improvement or inadequate was not including a policy at all - more than two thirds of local authorities did not have any available information for referrers or people with NRPF during the pandemic (see figure 4). For those that did, this could be inaccurate or misleading in a number of ways. 


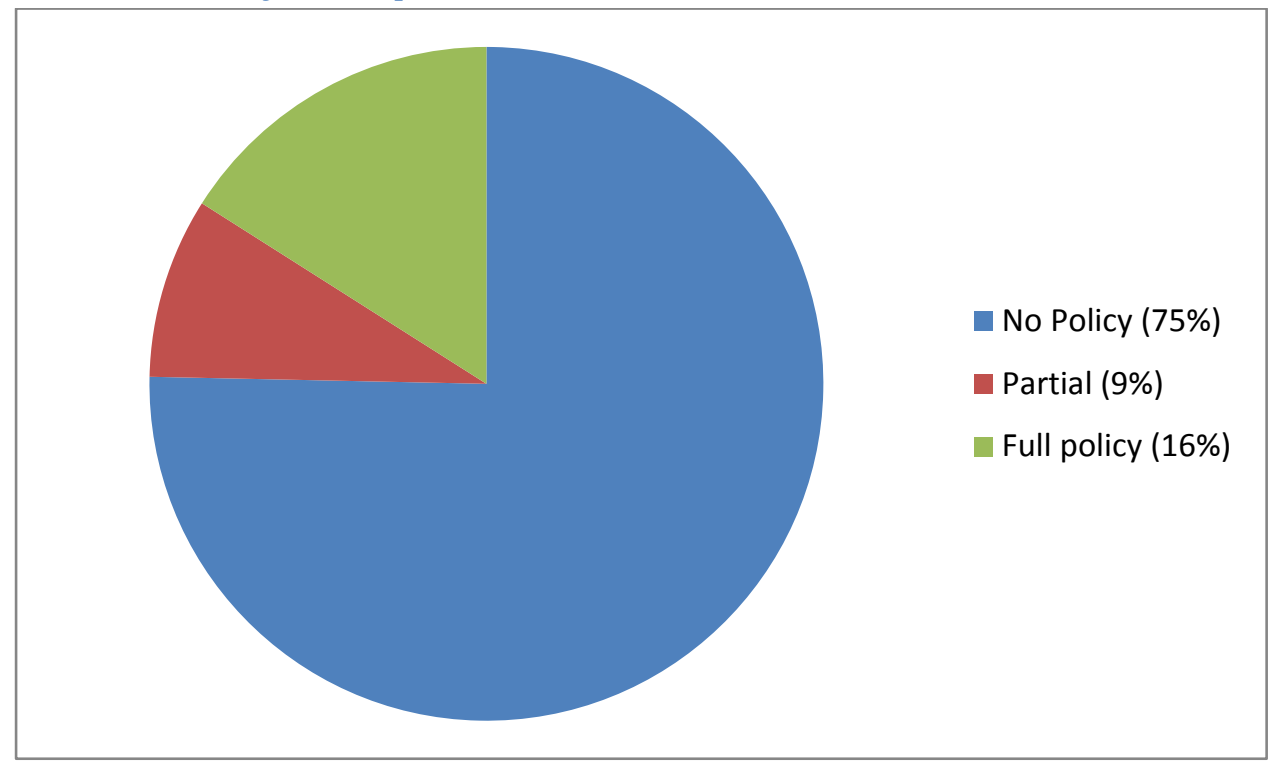

Figure 4: Local Authority COVID- 19 NRPF updates

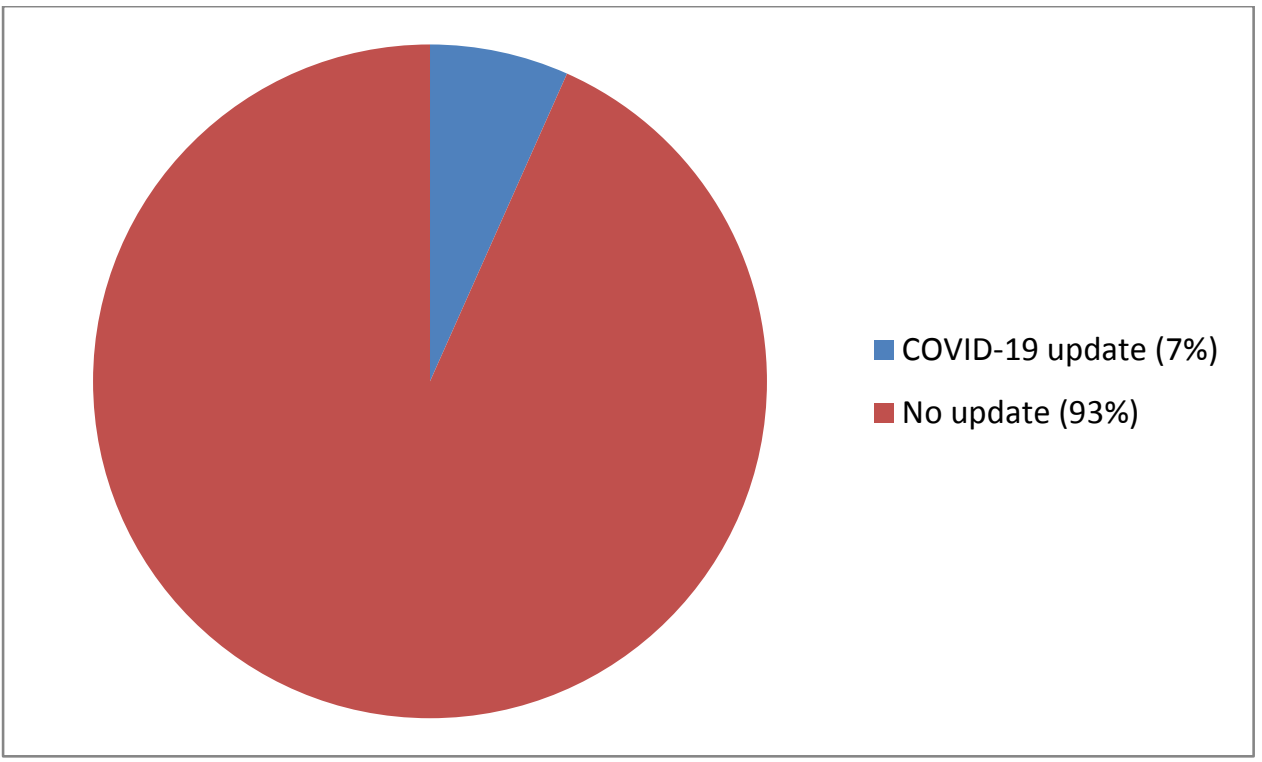

Initial analysis of documents on the websites of local authorities needing improvement or inadequate reveals a common perception that people with NRPF were a risk of fraud to the local authority. Barnsley Metropolitan Borough Council's website had only two references to people with NRPF, one of which was in an annual fraud report which stated that:

"Social care fraud has been identified nationally as an emerging fraud risk area for local authorities. Whilst this type of fraud can take many forms the areas of greatest concern are the misuse of personal budgets, and people with no recourse to public funds deceiving local authorities into providing services to them." (Barnsley, 2020).

Durham County Council did not have an NRPF policy, but listed 'Fraudulent claim of eligibility' for council services by people with NRPF as an Emerging / Increasing Fraud Risks (Durham 2018).

Rochdale Borough Council had also identified people with NRPF as one of the two 'emerging fraud risks' although this wasn't borne out by their own figures. Despite receiving 967 fraud referrals and 
having NRPF as a focus, they only identified 5 incidences. In comparison with 143 relating to council tax (Rochdale, 2017). Blackpool Borough Council outlined some examples of how this focus on fraud played out in practice:

"Several local authorities who identified that 'no recourse to public funds' was a risk have undertaken pro-active anti-fraud exercises in this area, including visiting recipients of the funds and undertaking fraud awareness exercises with those responsible administering the scheme." (Blackpool, 2020)

It is difficult to assess the extent to which a focus on people with NRPF as a fraud risk prevented people accessing services, but it is notable that only one of the local authorities who saw people with NRPF as a fraud risk had an NRPF policy or public details about an NRPF team.

Examples of missing or erroneous information included referring to out of date legislation when referring to legal responsibilities (Walsall, 2017). Hillingdon Borough Council had a broken link to an NRPF policy and outdated information about the DV concession. North Lincolnshire and East Riding of Yorkshire Council Website incorrectly said that people with NRPF are not eligible for early education.

\subsection{Call for evidence}

There were 71 responses to the call for evidence from every English region, Scotland and Wales, with the largest number of responses from London, reflecting the larger number of migrants and larger number of support organisations (see figure 5).

Figure 5: Regional breakdown of responses to call for evidence

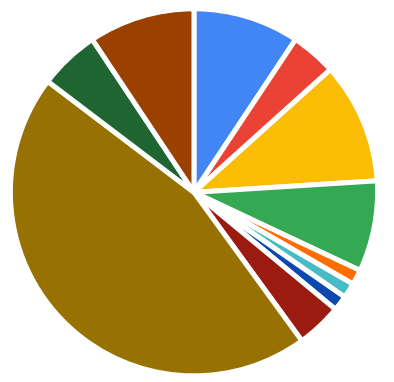

- West Midlands (9\%)

- South West (11\%)

- Wales (1\%)

- North East (1\%)

- London (45\%)

- East (9\%)
- Yorkshire and the Humber (4\%)

- South East (8\%)

- Scotland (1\%)

- North West (4\%)

- East Midlands (5\%) 


\subsubsection{Experiences of COVID-19}

Over half of organisations knew of service users who had been either been diagnosed with or had symptoms of COVID-19 (see figure 6).

Figure 6: Have service users been diagnosed or had COVID-19 symptoms?

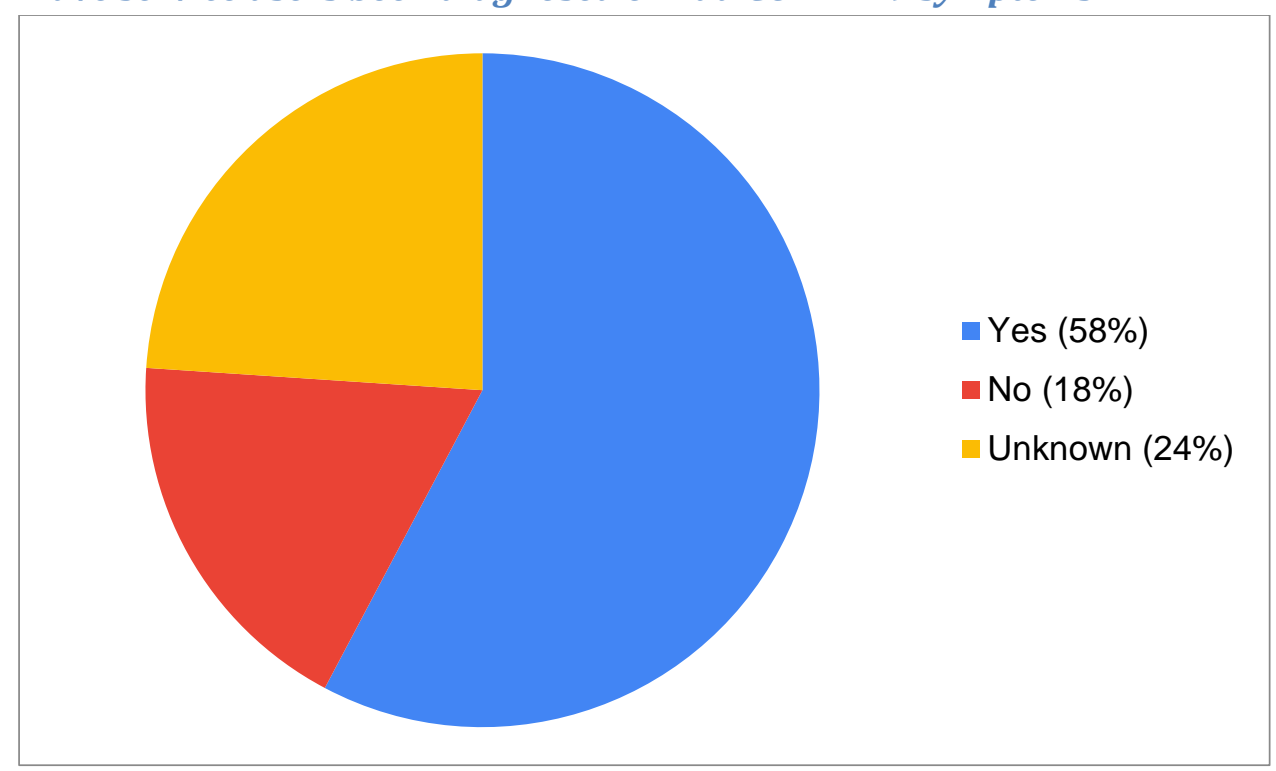

The total numbers of service users with COVID-19 symptoms were relatively low (See figure 7). 42 organisations responded to the question, and just over half knew of five or less people with COVID19 symptoms. However, this was not evenly distributed, and 2 organisations knew of over 20 people with symptoms.

Figure 7: If yes, please indicate approximately how many people

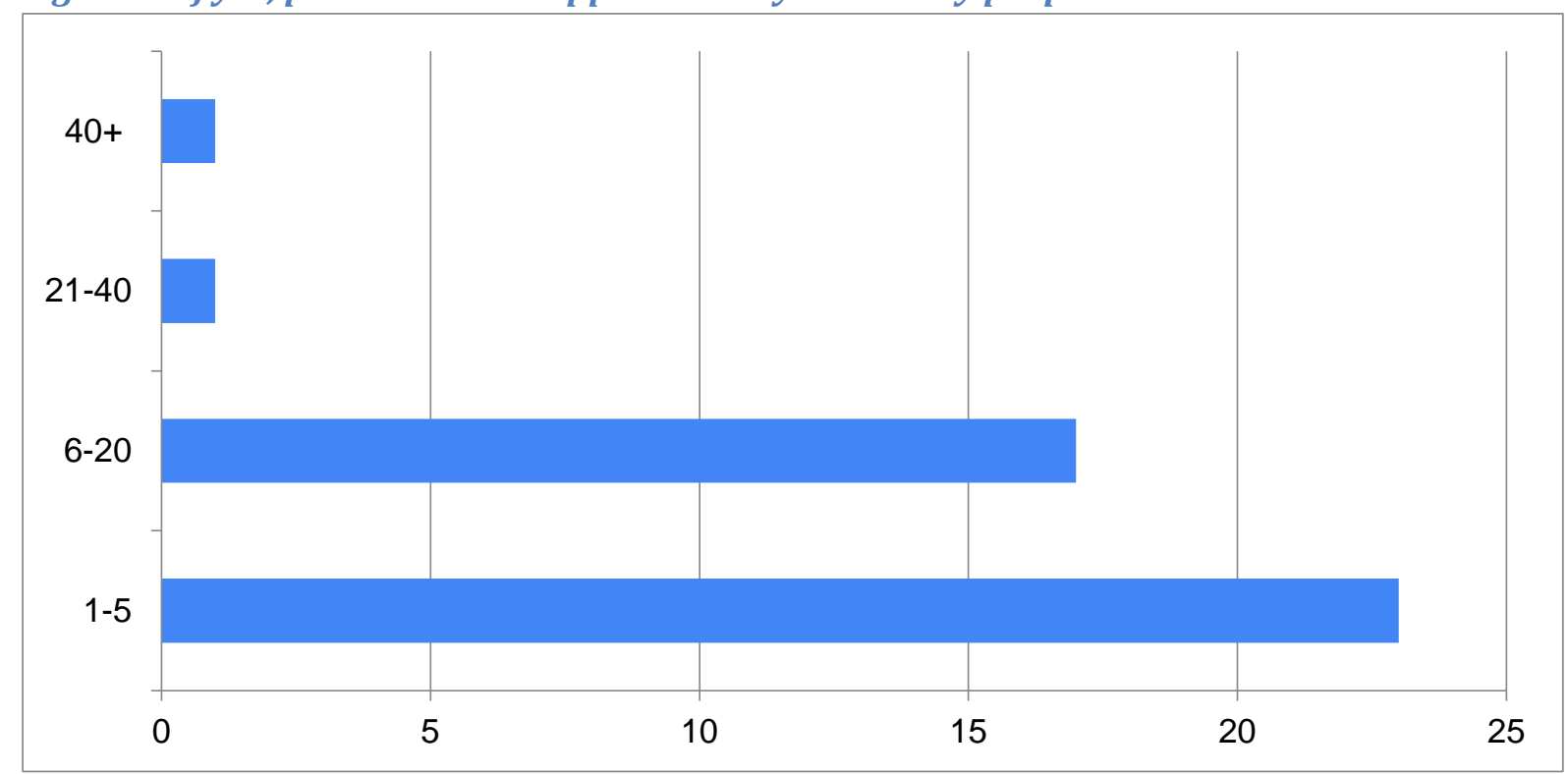

Although numbers of service users with COVID-19 were relatively low, their symptoms were particularly severe. Nearly a third of respondents did not know how severe the symptoms were, but 15 out of the remaining 34 knew of people who had died or become seriously ill (figure 8). 
Figure 8: Have any of your members/clients died or become seriously ill as a direct result of Covid-19?

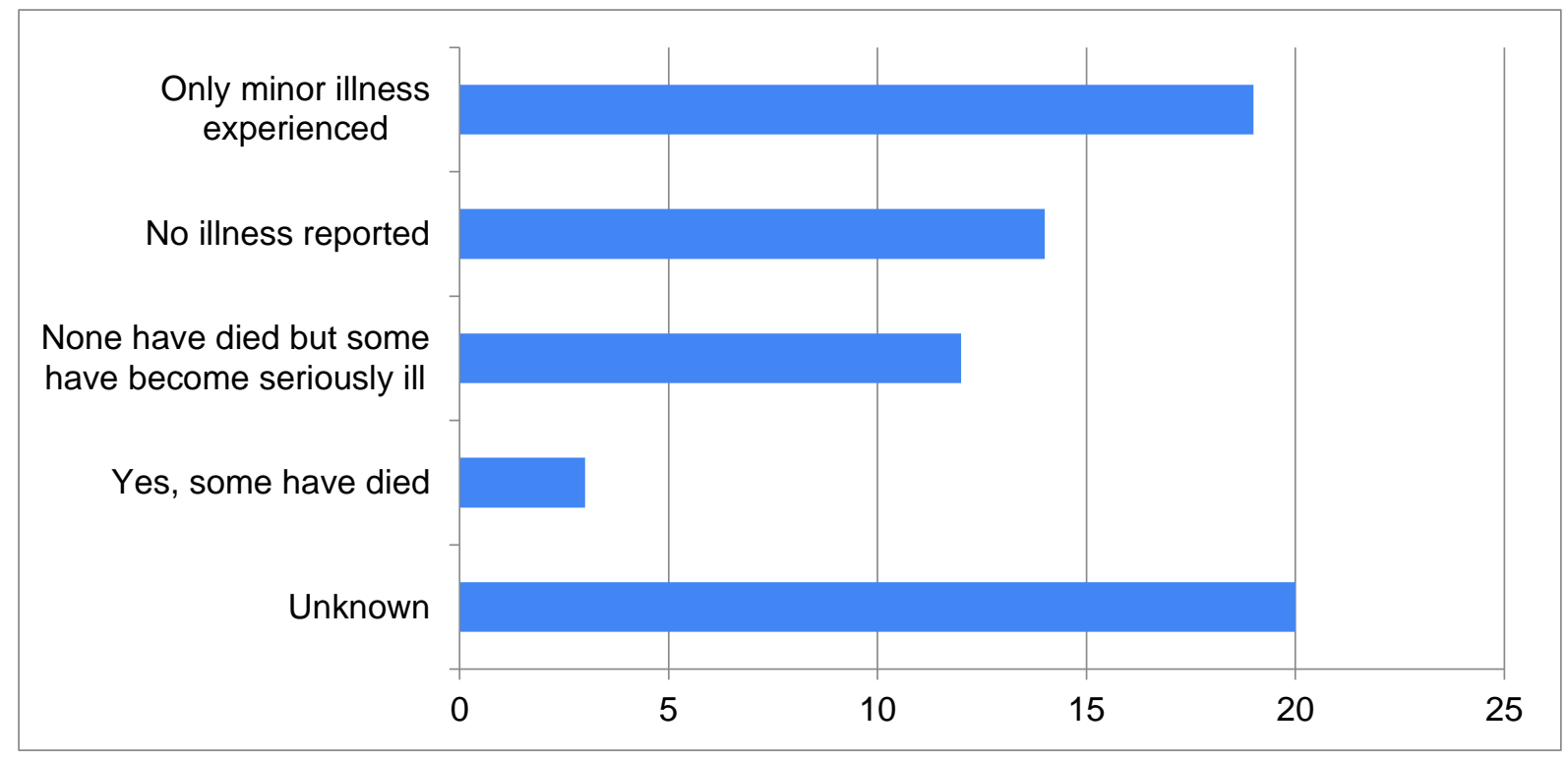

\subsubsection{Social impact of the pandemic}

In addition to those who experienced COVID-19 symptoms, there were a wide range of other social impacts experienced by service users (figure 9). The most commonly experienced problem was not having enough food (food security screening will be included in the phase 2 welfare diaries). This was closely followed by reduced support from support networks during the pandemic. Conversely, the least commonly reported problem was domestic abuse, although this is likely to be underreported, and was still reported by 11 organisations.

Figure 9: Social impact of COVID-19

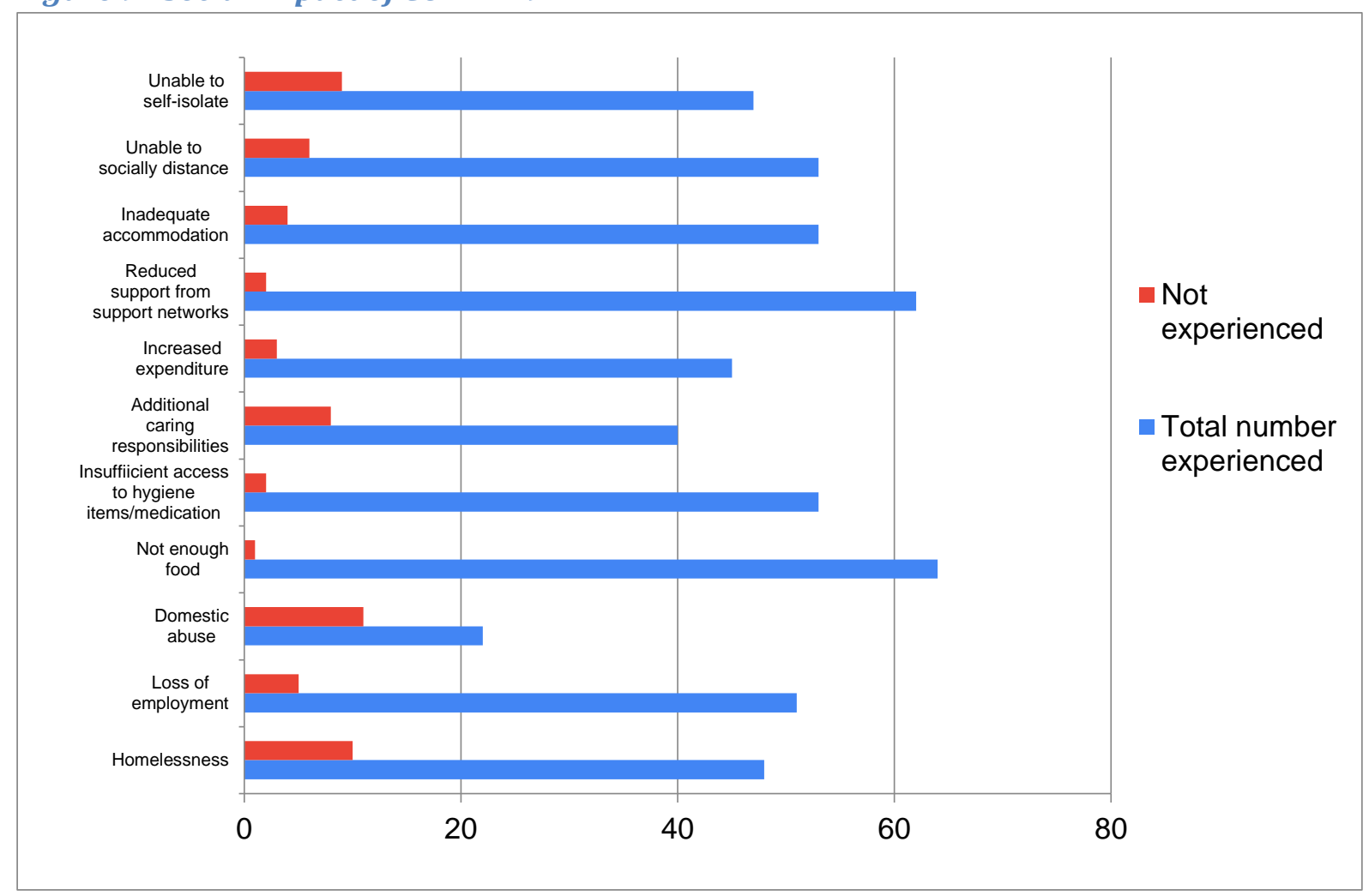


The pandemic had caused many service users who had previously not approached local authorities to request support, and organisations reported a range of barriers experienced by service users when attempting to access support (figure 10). The most common barrier across all service user groups was being told that no support was available. For people with NRPF who were experiencing homelessness, common barriers were being scared to access support because of their immigration status, and being unable to find out how to access support. In contrast, people attempting to access section n17 Children Act support or support under the Care Act were more commonly told to rely on support networks by the local authority.

\section{Figure 10: Access to support}

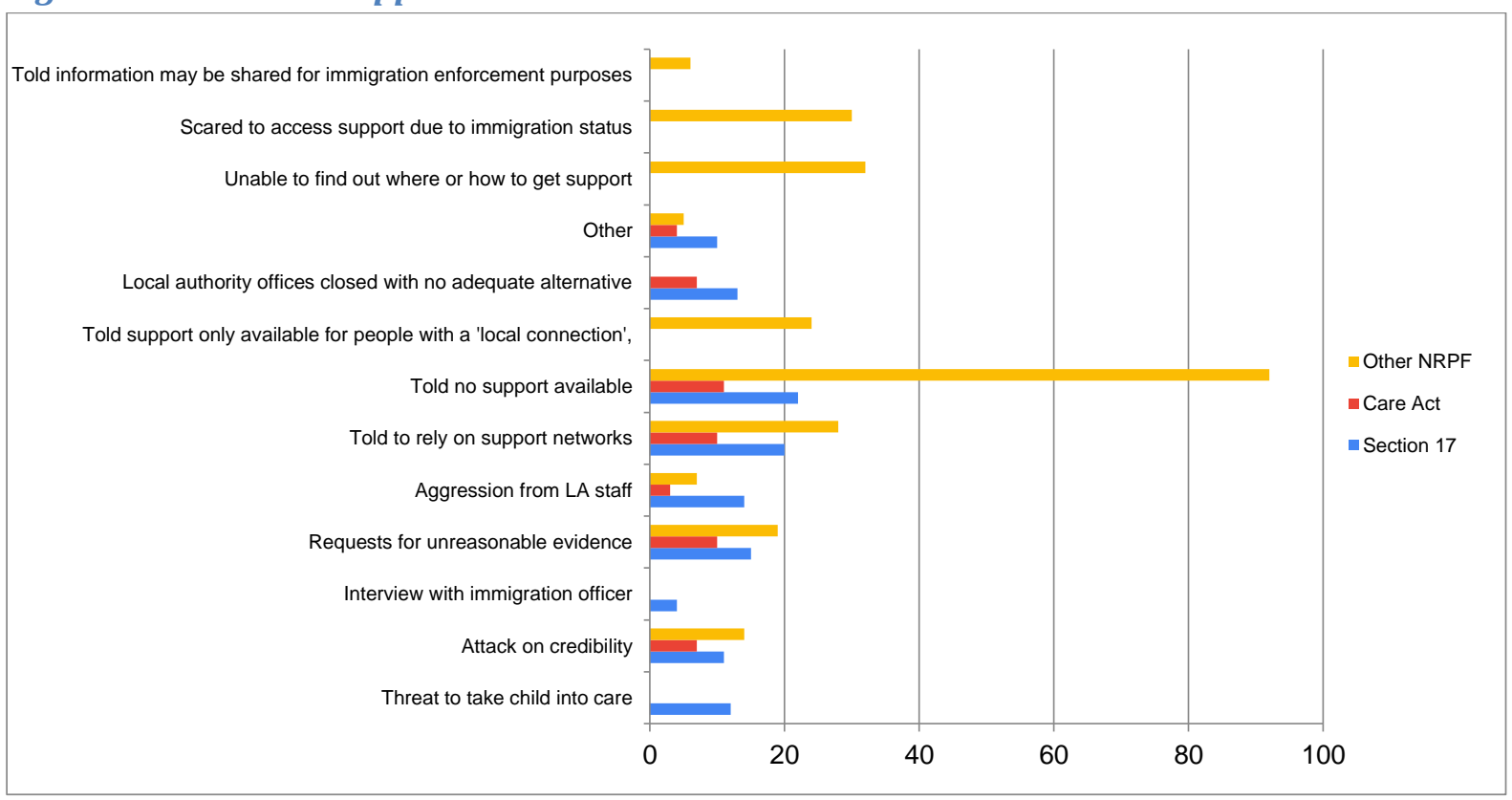

For service users who were already accessing support from a local authority, the challenges during the pandemic were different (figure 11). Inadequate accommodation which made it difficult to socially distance was the most common for families supported under section 17 , and for both those supported under the Care Act and the Children Act, being unable to contact social workers or other local authority workers was a frequently raised concern. 


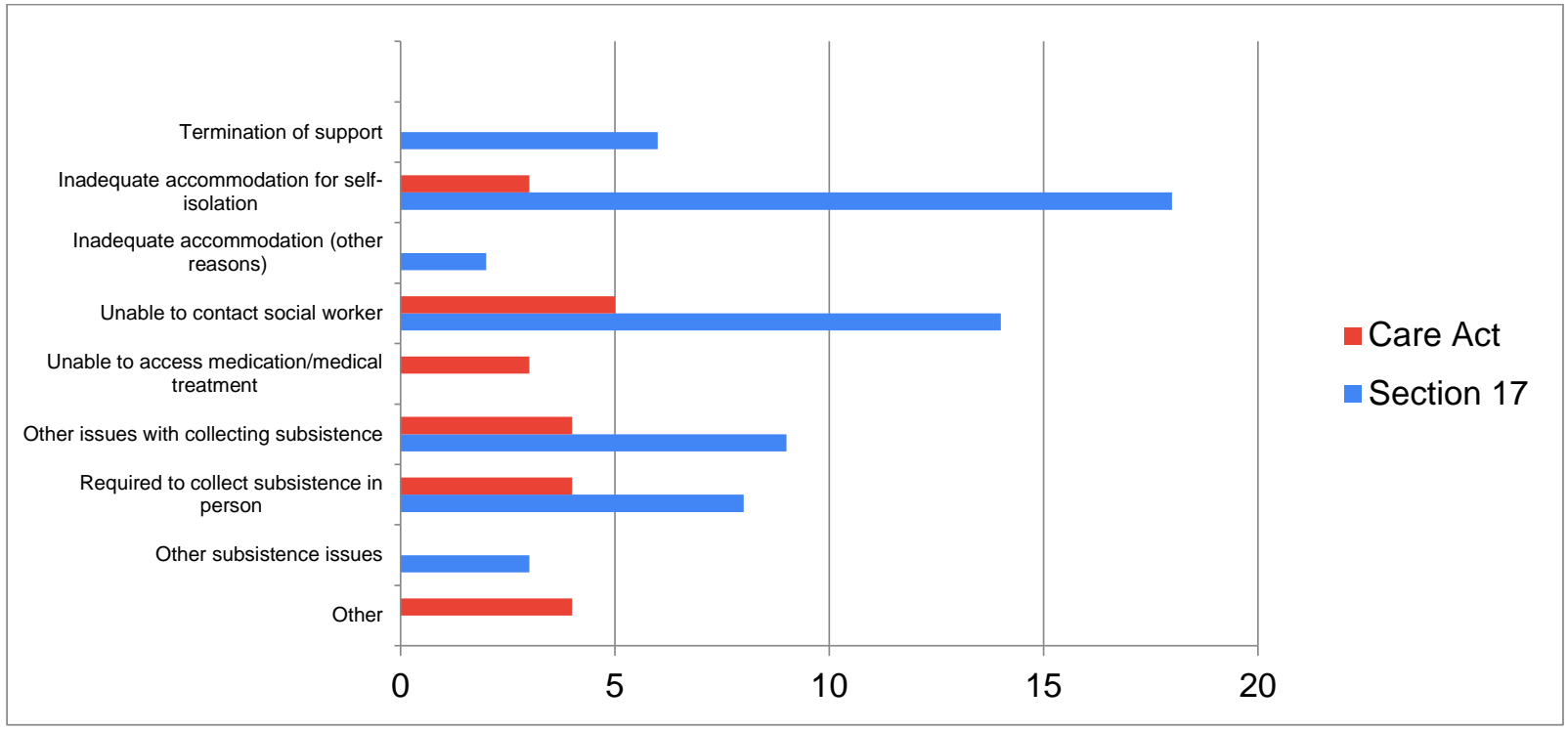

Those who had other support needs, most often homelessness, commonly found that they did not receive adequate provision for food or wider subsistence needs (figure 12).

Figure 12: Difficulties for those already accessing support (other support needs)

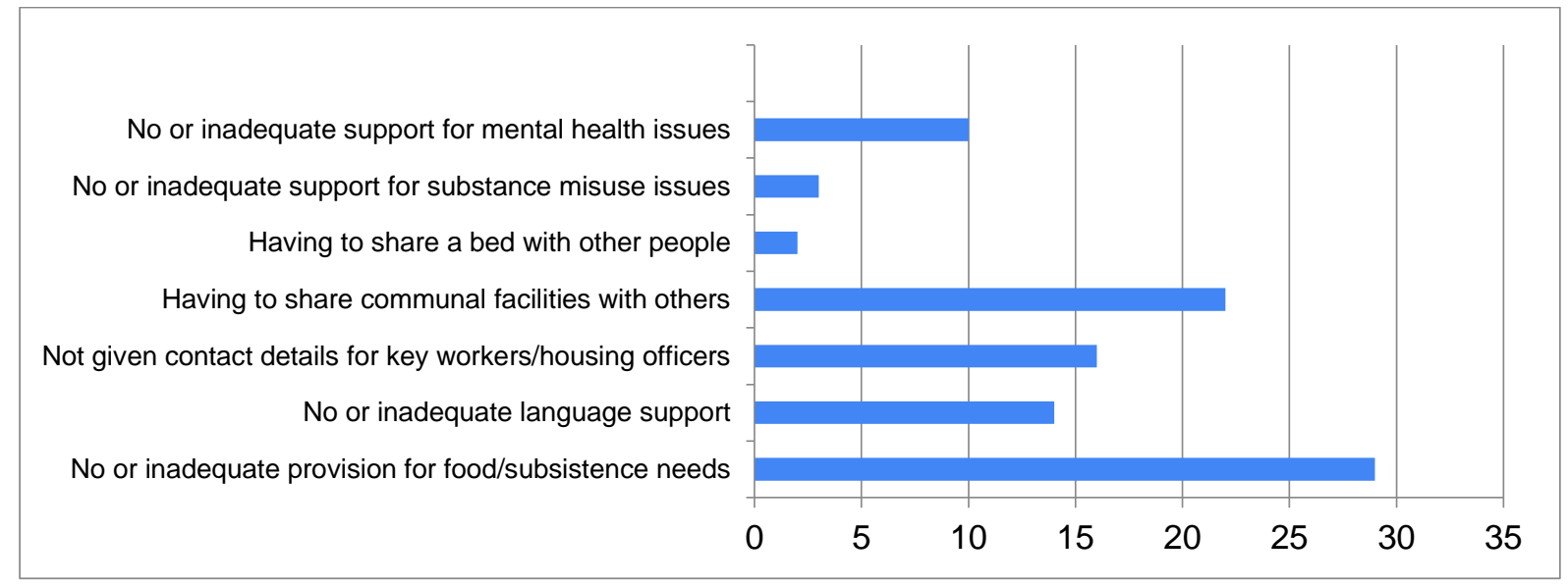

\subsubsection{Relationship with local authority}

Finally, organisations were asked about their relationship with local authorities during the pandemic. Out of 68 responses, only 17 local authorities had communicated an updated COVID-19 NRPF policy (figure 13). These were: Barking and Dagenham; Bristol; Brighton \& Hove; Coventry; Crawley; Croydon; Gateshead; Hackney; Haringey; Leicester City ; Manchester; Newcastle ; Newham Norfolk County; Norwich City; Southwark; Swansea. Only two of these authorities were identified as 'good' in the website survey, suggesting that local authorities were more willing to share policies privately with support organisations than to the general public. 


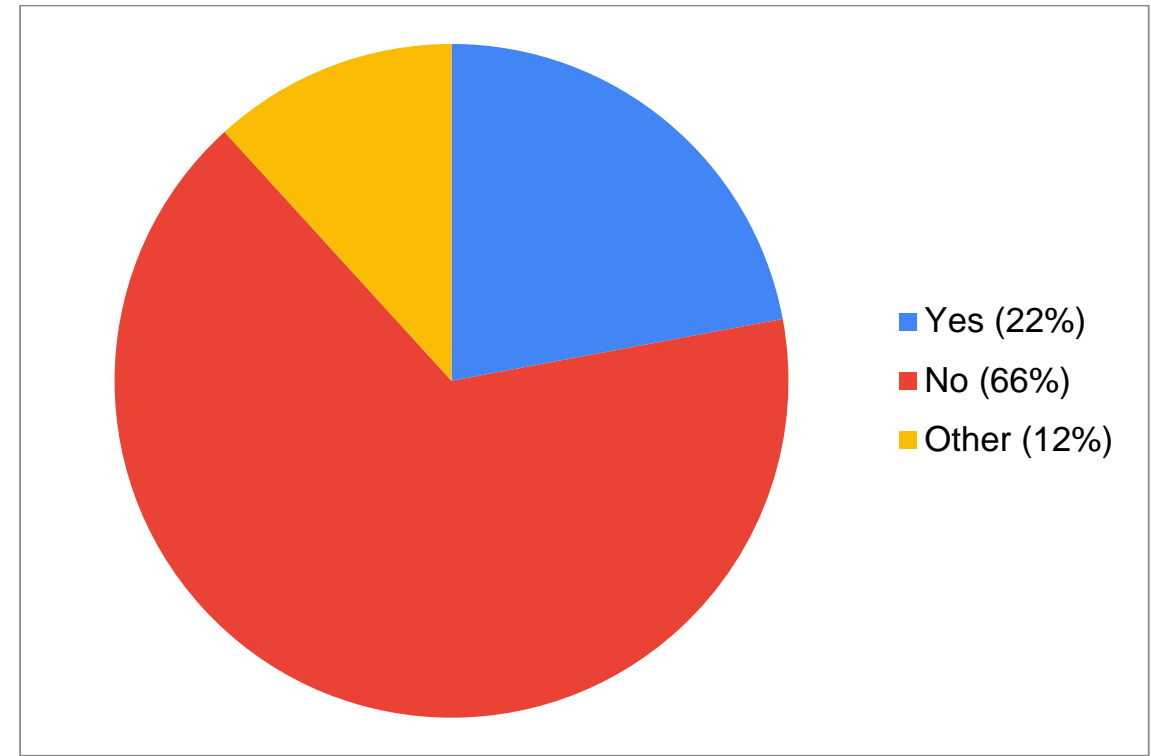

\section{Next steps}

- Development of local authority good practice case studies with examples of positive responses to the pandemic by local authorities.

- Data collection and analysis of the second round of local authority website surveys to assess changes in publicly available information.

- Welfare diaries to track experiences of household food security, health and wellbeing among people with NRPF.

- Final project report and webinar in July 2020.

For more information about this project, and to sign up for updates, please contact:

a.jolly@wlv.ac.uk 


\section{Appendix: Local authority website checklist}

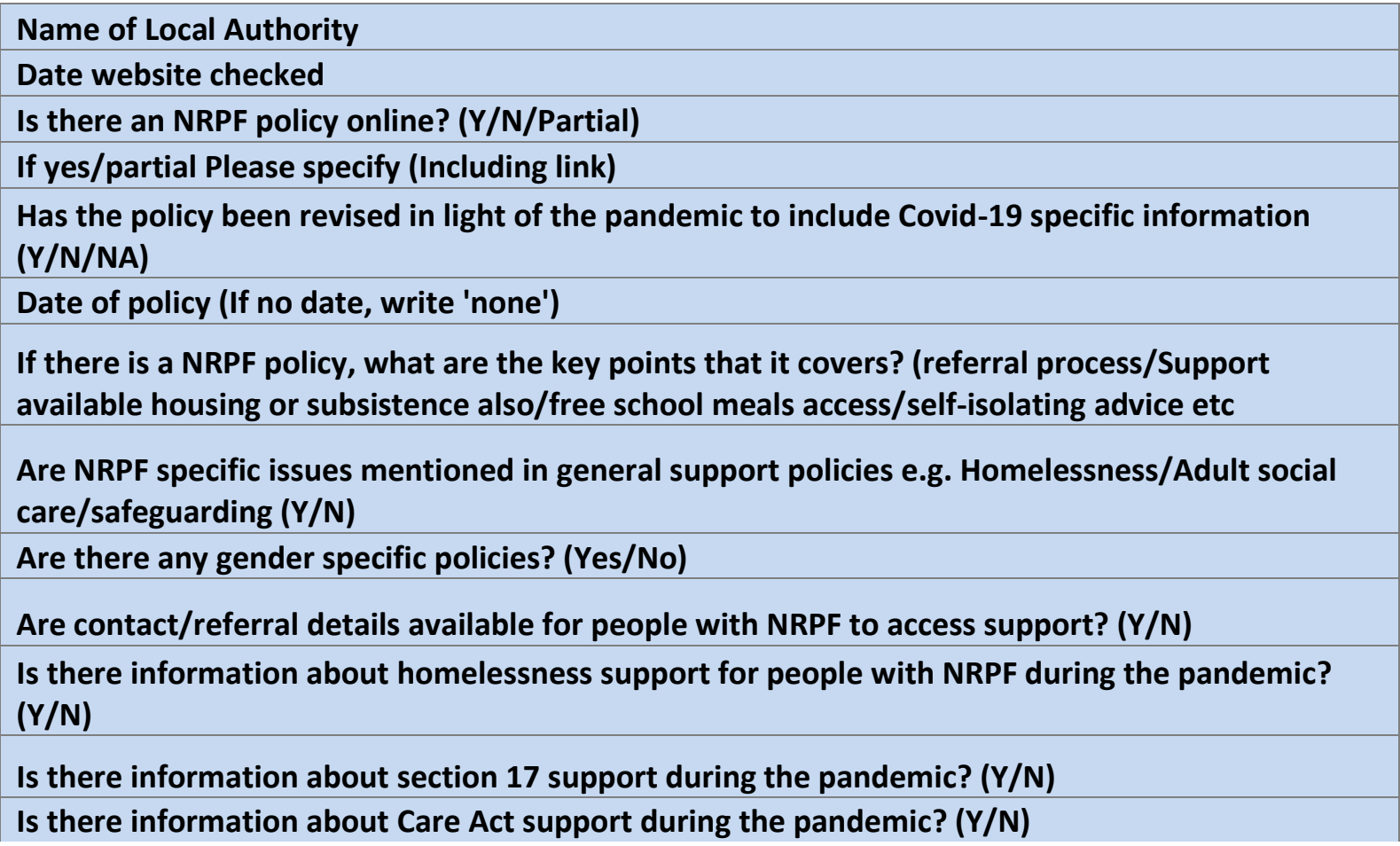


Appendix 2: Website scoring thresholds

\begin{tabular}{|l|l|}
\hline NRPF policy & 2 points \\
\hline Information short of a full policy & 1 point \\
\hline COVID-19 update & 1 point \\
\hline Inaccurate information & -2 points \\
\hline Specific information for different service user groups & 1 point for each \\
\hline Contact or referral details & 1 point \\
\hline
\end{tabular}




\section{References}

Children's Society, ASIRT, The Unity Project, South London Refugee Association \& Hackney Migrant Centre, 2020, Spotlight on NRPF: How No Recourse to Public Funds is harming children and families during the COVID-19 pandemic. Available at:

https://www.childrenssociety.org.uk/sites/default/files/spotlight-on-nrpf-a-collection-of-stories.pdf

Dickson, E., 2019, Not Seen, not heard: Children's experiences of the hostile environment. Project 17, London. Available at: https://www.project17.org.uk/media/70571/Not-seen-not-heard-1-.pdf

Durham County Council, 2018, Counter fraud and corruption strategy. Available at:

https://www.durham.gov.uk/media/1085/Counter-fraud-and-corruptionstrategy/pdf/CounterFraudAndCorruptionStrategy.pdf?m=636722734784900000

Farmer, N.J., 2017. "No Recourse to Public Funds", insecure immigration status and destitution: the role of social work? Critical and Radical Social Work, 5(3), pp.357-367. Available at:

http://dx.doi.org/10.1332/204986017X15029697778471.

Jolly, A., 2018, No recourse to social work? Statutory neglect, social exclusion and undocumented migrant families in the UK. Social Inclusion, 6(3), pp.190-200. Available at:

https://www.cogitatiopress.com/socialinclusion/article/view/1486

Mapp, C. 2017, No Recourse to public funds: An early help guide. Walsall Metropolitan Borough Council. Available at:

http://www.mywalsall.org/ckfinder/userfiles/files/No\%20Recourse\%20to\%20Public\%20Funds.pdf

MHCLC, 2020, Letter from Minister Hall to local authorities on plans to protect rough sleepers. HM Government. Available at:

https://assets.publishing.service.gov.uk/government/uploads/system/uploads/attachment data/file 1876466/Letter from Minister Hall to Local Authorities.pdf

Pinter, I., Compton, S., Parhar, R., \& Majid, H., 2020, A lifeline for all: Children and families with no recourse to public funds. Children's Society, London. Available at:

https://www.childrenssociety.org.uk/what-we-do/resources-and-publications/a-lifeline-for-all

Rochdale Borough Council, 2017, Internal Audit Annual Fraud Report 2016/17. Available at:

http://democracy.rochdale.gov.uk/documents/s55717/Internal\%20Audit\%20Annual\%20Fraud\%20R eport\%20201617.pdf 